\title{
An ultrapotent synthetic nanobody neutralizes SARS-CoV-2 by stabilizing inactive Spike
}

\author{
Michael Schoof ${ }^{1,2 *+}$, Bryan Faust ${ }^{1,2,3,4 *}$, Reuben A. Saunders ${ }^{1,5 *}$, Smriti Sangwan ${ }^{1,2 *}$, Veronica Rezelj6*, \\ Nick Hoppe ${ }^{3,4}$, Morgane Boone ${ }^{1,2}$, Christian B. Billesbølle ${ }^{3,4}$, Cristina Puchades ${ }^{4}$, Caleigh M. Azumaya ${ }^{4}$, \\ Huong T. Kratochvil ${ }^{4}$, Marcell Zimanyi ${ }^{1,2}$, Ishan Deshpande ${ }^{3,4}$, Jiahao Liang ${ }^{3}$, Sasha Dickinson ${ }^{4}$, \\ Henry C. Nguyen ${ }^{4}$, Cynthia M. Chio ${ }^{4}$, Gregory E. Merz ${ }^{4}$, Michael C. Thompson ${ }^{4}$, Devan Diwanji ${ }^{4}$, \\ Kaitlin Schaefer ${ }^{4}$, Aditya A. Anand ${ }^{1,2}$, Niv Dobzinski ${ }^{1,2}$, Beth Shoshana Zha ${ }^{7}$, Camille R. Simoneau ${ }^{8,9,10}$, \\ Kristoffer Leon ${ }^{8,9,10}$, Kris M. White ${ }^{1,12}$, Un Seng Chio ${ }^{4}$, Meghna Gupta ${ }^{4}$, Mingliang Jin ${ }^{4}$, Fei Li $^{4}$, Yanxin Liu ${ }^{4}$, \\ Kaihua Zhang ${ }^{4}$, David Bulkley ${ }^{4}$, Ming Sun ${ }^{4}$, Amber M. Smith ${ }^{4}$, Alexandrea N. Rizo ${ }^{4}$, Frank Moss ${ }^{4}$, \\ Axel F. Brilot ${ }^{4}$, Sergei Pourmal ${ }^{4}$, Raphael Trenker ${ }^{4}$, Thomas Pospiech ${ }^{4}$, Sayan Gupta ${ }^{13}$, Benjamin Barsi-Rhyne ${ }^{3}$, \\ Vladislav Belyy ${ }^{1,2}$, Andrew W. Barile-Hill14, Silke Nock ${ }^{1,2}$, Yuwei Liu', ${ }^{1,2}$ Nevan J. Krogan ${ }^{4,5,8,9}$, Corie Y. Ralston ${ }^{13}$, \\ Danielle L. Swaney ${ }^{4,5,8,9}$, Adolfo García-Sastre ${ }^{11,12,15,16}$, Melanie Ott ${ }^{8,9,10}$, Marco Vignuzzi $^{6}$, \\ QCRG Structural Biology Consortium ${ }^{4}$, Peter Walter ${ }^{1,2} \uparrow$, Aashish Manglik ${ }^{3,4,8,17} \uparrow$
}

\begin{abstract}
${ }^{1}$ Howard Hughes Medical Institute, University of California at San Francisco, San Francisco, CA, USA. ${ }^{2}$ Department of Biochemistry and Biophysics, University of California at San Francisco, San Francisco, CA, USA. ${ }^{3}$ Department of Pharmaceutical Chemistry, University of California at San Francisco, San Francisco, CA, USA. ${ }^{4}$ Quantitative Biosciences Institute (QBI) Coronavirus Research Group Structural Biology Consortium, University of California, San Francisco, CA, USA. ${ }^{5}$ Department of Cellular and Molecular Pharmacology, University of California at San Francisco, San Francisco, CA, USA. ${ }^{6}$ Viral Populations and Pathogenesis Unit, CNRS UMR 3569, Institut Pasteur, 75724 Paris Cedex 15, France. ${ }^{7}$ Department of Pulmonary, Critical Care, Allergy and Sleep Medicine, University of California San Francisco, San Francisco, CA, USA. ${ }^{8}$ Quantitative Biosciences Institute (QBI), University of California San Francisco, San Francisco, CA, USA. ${ }^{9}$. David Gladstone Institutes, San Francisco, CA, USA. ${ }^{10}$ Department of Medicine, University of California San Francisco, San Francisco, CA, USA. "'Department of Microbiology, Icahn School of Medicine at Mount Sinai, New York, NY, USA. ${ }^{22}$ Global Health and Emerging Pathogens Institute, Icahn School of Medicine at Mount Sinai, New York, NY, USA. ${ }^{13}$ Molecular Biophysics and Integrated Bioimaging and the Molecular Foundry, Lawrence Berkeley National Laboratory, Berkeley, CA, USA. ${ }^{14}$ Cytiva Life Sciences, Marlborough, MA, USA. ${ }^{15}$ Department of Medicine, Division of Infectious Diseases, Icahn School of Medicine at Mount Sinai, New York, NY, USA. ${ }^{16}$ The Tisch Cancer Institute, Icahn School of Medicine at Mount Sinai, New York, NY, USA. ${ }^{17}$ Department of Anesthesia and Perioperative Care, University of California at San Francisco, San Francisco, CA, USA.

*These authors contributed equally to this work. †Corresponding author. Email: michael@walterlab.ucsf.edu (M.S.); peter@walterlab.ucsf.edu (P.W.); Aashish.Manglik@ucsf.edu (A.M.) $¥ Q C R G$ Structural Biology Consortium collaborators and affiliations are listed in the supplementary materials.
\end{abstract}

The SARS-CoV-2 virus enters host cells via an interaction between its Spike protein and the host cell receptor angiotensin converting enzyme 2 (ACE2). By screening a yeast surface-displayed library of synthetic nanobody sequences, we developed nanobodies that disrupt the interaction between Spike and ACE2. Cryogenic electron microscopy (cryo-EM) revealed that one nanobody, Nb6, binds Spike in a fully inactive conformation with its receptor binding domains (RBDs) locked into their inaccessible down-state, incapable of binding ACE2. Affinity maturation and structure-guided design of multivalency yielded a trivalent nanobody, mNb6-tri, with femtomolar affinity for Spike and picomolar neutralization of SARSCoV-2 infection. mNb6-tri retains function after aerosolization, lyophilization, and heat treatment, which enables aerosol-mediated delivery of this potent neutralizer directly to the airway epithelia.

Over the last two decades, three zoonotic $\beta$-coronaviruses have entered the human population, causing severe respiratory symptoms with high mortality (1-3). The COVID-19 pandemic is caused by SARS-CoV-2, the most readily transmissible of these three coronaviruses (4-7). No preventive treatment has been approved for any coronavirus to date, and the timeline for an effective and broadly available vaccine for SARS-CoV-2 remains uncertain. The development of novel therapeutic and prophylactic approaches thus remains essential.

Coronavirus virions are bounded by a membrane that contains the homotrimeric transmembrane glycoprotein Spike responsible for virus entry into the host cell $(8,9)$. The surface-exposed portion of Spike is composed of two domains, $S_{1}$ and $S_{2}(10)$. $S_{1}$ binds the host cell receptor angiotensin converting enzyme 2 (ACE2), while $\mathrm{S}_{2}$ catalyzes fusion of the viral and host cell membranes (11-13). Contained within $\mathrm{S}_{1}$ is the receptor binding domain (RBD), which directly binds to ACE2, and the N terminal domain (NTD). The RBD is attached to the body of Spike by a flexible region and can exist in an inaccessible down-state or an accessible up-state (14, 15). Binding to ACE2 requires the RBD to occupy the up-state and enables cleavage by host proteases, triggering a conformational change in $\mathrm{S}_{2}$ required for viral entry (16). In SARSCoV-2 virions, Spike exchanges between an active, open conformation with at least one RBD in the up-state and an 
inactive, closed conformation with all RBDs in the down-state $(8,9)$.

We isolated single domain antibodies (nanobodies) that neutralize SARS-CoV-2 by screening a yeast surface-displayed library of $>2 \times 10^{9}$ synthetic nanobody sequences for binders to the Spike ectodomain (17). We used a mutant form of SARSCoV-2 Spike $\left(\right.$ Spike $\left.^{\mathrm{S} 2 \mathrm{P}}\right)$ as the antigen (15). Spike ${ }^{\mathrm{S} 2 \mathrm{P}}$ lacks one of the two proteolytic cleavage sites between the $S_{1}$ and $S_{2}$ domains and introduces two mutations and a trimerization domain to stabilize the pre-fusion conformation. We labeled Spike $^{\mathrm{S2P}}$ with biotin or with fluorescent dyes and selected nanobody-displaying yeast over multiple rounds, first by magnetic bead binding and then by fluorescence-activated cell sorting (Fig. 1A).

Three rounds of selection yielded 21 unique nanobodies that bound Spike ${ }^{\mathrm{S} 2 \mathrm{P}}$ and showed decreased binding in the presence of a dimeric construct of the ACE2 extracellular domain (ACE2-Fc). These nanobodies fall into two classes. Class I binds the RBD and competes directly with ACE2-Fc (Fig. 1B). A prototypical example of this class is nanobody $\mathrm{Nb} 6$, which binds to Spike ${ }^{\mathrm{S} 2 \mathrm{P}}$ and to RBD alone with a $\mathrm{K}_{\mathrm{D}}$ of $210 \mathrm{nM}$ and $41 \mathrm{nM}$, respectively (Fig. $1 \mathrm{C}$ and table S1). Class II, exemplified by nanobody $\mathrm{Nb3}$, binds to Spike ${ }^{\mathrm{S} 2 \mathrm{P}}\left(\mathrm{K}_{\mathrm{D}}=61 \mathrm{nM}\right)$, but displays no binding to RBD alone (Fig. $\mathrm{IC}$ and table S1). In the presence of excess ACE2-Fc, binding of $\mathrm{Nb} 6$ and other Class I nanobodies is blocked entirely, whereas binding of $\mathrm{Nb} 3$ and other Class II nanobodies is moderately decreased (Fig. 1B). These results suggest that Class I nanobodies target the RBD to block ACE2 binding, whereas Class II nanobodies target other epitopes. Indeed, surface plasmon resonance (SPR) experiments demonstrate that Class I and Class II nanobodies can bind Spike ${ }^{\mathrm{S} 2 \mathrm{P}}$ simultaneously (Fig. 1D).

Class I nanobodies show a consistently faster association rate constant $\left(k_{a}\right)$ for nanobody binding to the isolated RBD than to Spike ${ }^{\mathrm{S} 2 \mathrm{P}}$ (table S1), which suggests that RBD accessibility influences the $\mathrm{K}_{\mathrm{D}}$. We next tested the efficacy of Class I and Class II nanobodies to inhibit binding of fluorescently labeled Spike ${ }^{\mathrm{S} 2 \mathrm{P}}$ to ACE2-expressing HEK293 cells (Fig. 1E and table S1). Class I nanobodies $\mathrm{Nb} 6$ and $\mathrm{Nb} 11$ emerged as two of the most potent clones with $\mathrm{IC}_{50}$ values of 370 and $540 \mathrm{nM}$, respectively. Class II nanobodies showed little to no activity in this assay. We prioritized two Class I nanobodies, $\mathrm{Nb} 6$ and $\mathrm{Nb} 11$, that combine potent Spike ${ }^{\mathrm{S} 2 \mathrm{P}}$ binding with relatively small differences in $k_{a}$ between binding to Spike ${ }^{\mathrm{S} 2 \mathrm{P}}$ or RBD. For Class II nanobodies, we prioritized Nb3 because of its relative yield during purification (table S1).

To define the binding sites of $\mathrm{Nb} 6$ and Nb11, we determined their cryogenic electron microscopy (cryo-EM) structures bound to Spike ${ }^{\mathrm{S} 2 \mathrm{P}}$ (Fig. 2, A and B; figs. S1 to S3; and table S2). Both nanobodies recognize RBD epitopes that overlap the ACE2 binding site (Fig. 2E). For Nb6 and Nb11, we resolved nanobody binding to both the open and closed conformations of Spike ${ }^{\mathrm{S} 2 \mathrm{P}}$. We obtained a $3.0 \AA$ map of $\mathrm{Nb} 6$ bound to closed Spike ${ }^{\mathrm{S} 2 \mathrm{P}}$, which enabled modeling of the Nb6Spike ${ }^{\mathrm{S} 2 \mathrm{P}}$ complex (Fig. 2A), including the complementarity determining regions (CDRs). We also obtained lower resolution

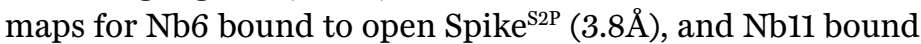
to open and closed Spike ${ }^{\mathrm{S} 2 \mathrm{P}}(4.2 \AA$, and $3.7 \AA$, respectively). For these lower resolution maps, we could define the nanobody's binding orientation but not accurately model the CDRs.

$\mathrm{Nb} 6$ bound to closed Spike ${ }^{\mathrm{S} 2 \mathrm{P}}$ straddles the interface between two adjacent RBDs. The majority of the contacting surfaces are contributed by CDR1 and CDR2 of Nb6 (Fig. 2C). CDR3 contacts the adjacent RBD positioned counterclockwise when viewed from the top (Fig. 2C). The binding of one Nb6 therefore stabilizes two adjacent RBDs in the down-state and likely pre-organizes the binding site for a second and third Nb6 molecule to stabilize the closed Spike conformation. By contrast, Nb11 bound to down-state RBDs only contacts a single RBD (Fig. 2D).

The structure of $\mathrm{Nb} 6$ bound to closed Spike ${ }^{\mathrm{S} 2 \mathrm{P}}$ enabled us to engineer bivalent and trivalent nanobodies predicted to lock all RBDs in the down-state. We inserted flexible Gly-Ser linkers of either 15 or 20 amino acids to span the $52 \AA$ distance between adjacent $\mathrm{Nb} 6$ monomers bound to down-state RBDs in closed Spike ${ }^{\mathrm{S} 2 \mathrm{P}}$ (fig. S4). These linkers are too short to span the $72 \AA$ distance between $\mathrm{Nb} 6$ molecules bound to open Spike. Moreover, steric clashes would prevent binding of three RBDs in open Spike with a single up-state RBD even with longer linker length (fig. S4). By contrast, the minimum distance between adjacent Nb11 monomers bound to either open or closed Spike ${ }^{\mathrm{S} 2 \mathrm{P}}$ is $68 \AA$. We predicted that multivalent binding by $\mathrm{Nb} 6$ constructs would display significantly slowed dissociation rates due to enhanced avidity.

In SPR experiments, both bivalent $\mathrm{Nb} 6$ with a 15 amino acid linker (Nb6-bi) and trivalent $\mathrm{Nb} 6$ with two 20 amino acid linkers (Nb6-tri) dissociate from Spike ${ }^{\mathrm{S} 2 \mathrm{P}}$ in a biphasic manner. The dissociation phase can be fitted to two components: a fast phase with kinetic rate constants $k_{d 1}$ of $2.7 \times 10^{-2} \mathrm{~s}^{-1}$ for Nb6-bi and $2.9 \times 10^{-2} \mathrm{~s}^{-1}$ for $\mathrm{Nb} 6$-tri, which are close to that observed for monovalent $\mathrm{Nb} 6\left(k_{d}=5.6 \times 10^{-2} \mathrm{~s}^{-1}\right)$ and a slow phase that is dependent on avidity $\left(k_{d 2}=3.1 \times 10^{-4} \mathrm{~s}^{-1}\right.$ for $\mathrm{Nb} 6$-bi and $k_{d 2}<1.0 \times 10^{-6} \mathrm{~S}^{-1}$ for $\mathrm{Nb} 6$-tri, respectively) (Fig. 3A). The relatively similar $k_{d}$ for the fast phase suggests that a fraction of the observed binding for the multivalent constructs is nanobody binding to a single Spike ${ }^{\mathrm{S} 2 \mathrm{P}} \mathrm{RBD}$. By contrast, the slow dissociation phase of $\mathrm{Nb} 6$-bi and $\mathrm{Nb} 6$-tri indicates engagement of two or three RBDs. We observed no dissociation for the slow phase of $\mathrm{Nb} 6$-tri over $10 \mathrm{~min}$, indicating an upper boundary for $k_{d 2}$ of $1 \times 10^{-6} \mathrm{~s}^{-1}$ and subpicomolar affinity. This measurement remains an upper boundary estimate because the measurement is limited by the intrinsic dissociation rate of Spike ${ }^{\mathrm{S} 2 \mathrm{P}}$ from the SPR chip imposed by the chemistry used to immobilize Spike ${ }^{\mathrm{S} 2 \mathrm{P}}$. The true dissociation rate, therefore, 
may be significantly lower.

Biphasic dissociation could be explained by a slow interconversion between up- and down-state RBDs, with conversion to the more stable down-state required for multivalent binding: a single domain of $\mathrm{Nb} 6$-tri engaged with an up-state RBD would dissociate rapidly. The system would then reequilibrate as the RBD flips into the down-state, eventually allowing Nb6-tri to trap all RBDs in closed Spike ${ }^{\mathrm{S} 2 \mathrm{P}}$. To test this directly, we varied the association time for Nb6-tri binding to Spike ${ }^{\mathrm{S} 2 \mathrm{P}}$. Indeed, we observed an exponential decrease in the percent fast-phase with a $t_{1 / 2}$ of $65 \mathrm{~s}$ (Fig. 3B), which, we surmise, reflects the timescale of conversion between the RBD up- and down-states in Spike ${ }^{\mathrm{S} 2 \mathrm{P}}$. Taken together, dimerization and trimerization of $\mathrm{Nb} 6$ afforded 750-fold and $>200,000$-fold gains in $K_{D}$, respectively.

Unable to determine the binding site of $\mathrm{Nb} 3$ by cryo-EM, we turned to radiolytic hydroxyl radical footprinting. We exposed apo- or Nb3-bound Spike ${ }^{\mathrm{S} 2 \mathrm{P}}$ to synchrotron X-ray radiation to label solvent-exposed amino acids with hydroxyl radicals, which we subsequently quantified by mass spectrometry of protease digested Spike ${ }^{\mathrm{S} 2 \mathrm{P}}$ (18). Two neighboring surface residues on the $\mathrm{S}_{1} \mathrm{~N}$-terminal domain of Spike (M177 and $\mathrm{H} 207$ ) were protected in the presence of $\mathrm{Nb} 3$ at a level consistent with prior observations of antibody-antigen interactions by hydroxyl radical footprinting (fig. S5) (19). Previously discovered coronavirus neutralizing antibodies bind an epitope within the N-terminal domain of Spike with Fab fragments that are non-competitive with the host cell receptor $(20,21)$. Further SPR experiments demonstrated that $\mathrm{Nb} 3$ can bind Spike ${ }^{\mathrm{S} 2 \mathrm{P}}$ simultaneously with monovalent ACE2 (fig. S6). We hypothesized that multivalent display of $\mathrm{Nb} 3$ on the surface of yeast may account for the partial decrease in Spike ${ }^{\mathrm{S} 2 \mathrm{P}}$ binding observed in the presence of ACE2-Fc. Indeed, a trivalent construct of $\mathrm{Nb} 3$ with 15 amino acid linkers (Nb3-tri) inhibited Spike ${ }^{\mathrm{S} 2 \mathrm{P}}$ binding to ACE2 cells with an $\mathrm{IC}_{50}$ of $41 \mathrm{nM}$ (fig. S6). How Nb3-tri disrupts Spike-ACE2 interactions remains unclear.

We next tested the neutralization activity of monovalent and trivalent versions of our top Class I ( $\mathrm{Nb} 6$ and $\mathrm{Nb} 11$ ) and Class II (Nb3) nanobodies against SARS-CoV-2 pseudotyped lentivirus using a previously described assay (22). $\mathrm{Nb} 6$ and Nb11 inhibited pseudovirus infection with $\mathrm{IC}_{50}$ values of $2.0 \mu \mathrm{M}$ and $2.4 \mu \mathrm{M}$, respectively. $\mathrm{Nb} 3$ inhibited pseudovirus infection with an $\mathrm{IC}_{50}$ of $3.9 \mu \mathrm{M}$ (Fig. $3 \mathrm{C}$ and table $\mathrm{S} 1$ ). Nb6-tri shows a 2000-fold enhancement of inhibitory activity, with an $\mathrm{IC}_{50}$ of $1.2 \mathrm{nM}$, whereas trimerization of $\mathrm{Nb} 11$ and $\mathrm{Nb} 3$ resulted in more modest gains of 40- and 10-fold (51nM and 400nM), respectively (Fig. 3C). We confirmed these neutralization activities with a viral plaque assay using live SARS$\mathrm{CoV}-2$ virus infection of VeroE6 cells. Here, Nb6-tri proved exceptionally potent, neutralizing SARS-CoV-2 with an average $\mathrm{IC}_{50}$ of $160 \mathrm{pM}$ (Fig. 3D). Nb3-tri neutralized SARS-CoV-2 with an average $\mathrm{IC}_{50}$ of $140 \mathrm{nM}$ (Fig. 3D).

We further optimized the potency of $\mathrm{Nb} 6$ by selecting a saturation mutagenesis library targeting all three CDRs. Two rounds of selection identified high-affinity clones with two penetrant mutations: I27Y in CDR1 and P105Y in CDR3. We incorporated these mutations into $\mathrm{Nb} 6$ to generate matured $\mathrm{Nb} 6$ (mNb6), which binds with 500 -fold increased affinity to Spike $^{\mathrm{S} 2 \mathrm{P}}$ (Fig. 4A). mNb6 inhibits both pseudovirus and live SARS-CoV-2 infection with low nanomolar potency, a 200fold improvement compared to $\mathrm{Nb} 6$ (Fig. 4B and table $\mathrm{S} 1$ ).

A $2.9 \AA$ cryo-EM structure shows that $\mathrm{mNb} 6$ binds to closed Spike $^{\mathrm{S} 2 \mathrm{P}}$ (Fig. 4C and fig. S7). $\mathrm{mNb} 6$ induces a slight rearrangement of the down-state RBDs as compared to Spike $^{\mathrm{S} 2 \mathrm{P}}$ bound to $\mathrm{Nb} 6$, inducing a $9^{\circ}$ rotation of the $\mathrm{RBD}$ away from the central three-fold symmetry axis. This deviation likely arises from a different interaction between CDR3 and Spike ${ }^{\mathrm{S} 2 \mathrm{P}}$, which nudges the RBDs into a new resting position (Fig. 4D). While the I27Y substitution optimizes local contacts between CDR1 in its original binding site on the $\mathrm{RBD}$, the P105Y substitution leads to a marked rearrangement of CDR3 in mNb6 (Fig. 4, E and F). This conformational change yields a different set of contacts between mNb6 CDR3 and the adjacent RBD. An X-ray crystal structure of $\mathrm{mNb} 6$ alone revealed dramatic conformational differences in CDR1 and CDR3 between free and Spike ${ }^{\mathrm{S} 2 \mathrm{P}}$-bound $\mathrm{mNb} 6$ (Fig. 4G and table S3). Although differences in loop conformation in the crystal structure may arise from crystal lattice contacts, they are suggestive of conformational heterogeneity for unbound $\mathrm{mNb} 6$ and induced-fit rearrangements upon binding to Spike $^{\mathrm{S} 2 \mathrm{P}}$.

The binding orientation of $\mathrm{mNb} 6$ is similar to that of $\mathrm{Nb} 6$, suggesting that multivalent design would likewise enhance binding affinity. Unlike $\mathrm{Nb} 6$-tri, trivalent $\mathrm{mNb} 6$ with a 20 amino acid linker (mNb6-tri) bound to $\mathrm{Spike}^{\mathrm{S} 2 \mathrm{P}}$ with no observable fast-phase dissociation and no measurable dissociation over ten minutes, yielding an upper bound for the dissociation rate constant $k_{d}$ of $1.0 \times 10^{-6} \mathrm{~S}^{-1}\left(\mathrm{t}_{1 / 2}>8\right.$ days) and a $\mathrm{K}_{\mathrm{D}}$ of $<1 \mathrm{pM}$ (Fig. 4A). mNb6-tri displays further gains in potency in both pseudovirus and live SARS-CoV-2 infection assays with $\mathrm{IC}_{50}$ values of $120 \mathrm{pM}(5.0 \mathrm{ng} / \mathrm{mL})$ and $54 \mathrm{pM}$ $(2.3 \mathrm{ng} / \mathrm{mL})$, respectively (Fig. 4B and table S1). Given the subpicomolar affinity observed by SPR, it is likely that these viral neutralization potencies reflect the lower limit of the assays. $\mathrm{mNb} 6$-tri is therefore an exceptionally potent SARS-CoV-2 neutralizing molecule.

We next tested whether viral neutralization by the Class I nanobody $\mathrm{mNb} 6$ is potentially synergistic with the Class II nanobody $\mathrm{Nb3}$-tri. In pseudovirus neutralization assays, we observed an additive effect when combining Nb3-tri with $\mathrm{mNb} 6$ (fig. S8). However, the potency for $\mathrm{mNb} 6$ viral neutralization was unchanged with increasing concentrations of Nb3-tri, suggesting minimal synergy between these two 
nanobodies.

We next tested $\mathrm{Nb} 6$ and its derivatives for stability. Circular dichroism revealed melting temperatures of $66.9,62.0$, 67.6, and $61.4^{\circ} \mathrm{C}$ for $\mathrm{Nb} 6, \mathrm{Nb} 6$-tri, $\mathrm{mNb} 6$ and $\mathrm{mNb} 6$-tri, respectively (fig. S9). Moreover, $\mathrm{mNb} 6$ and $\mathrm{mNb} 6$-tri were stable to lyophilization and to aerosolization, showing no aggregation by size exclusion chromatography and preserved high affinity binding to Spike ${ }^{\mathrm{S} 2 \mathrm{P}}$ (Fig. 5, A and B, and fig. S9). Finally, mNb6-tri retains potent inhibition of pseudovirus and live SARS-CoV-2 infection after aerosolization, lyophilization, or heat treatment for 1 hour at $50^{\circ} \mathrm{C}$ (Fig. $5 \mathrm{C}$ and fig. S9).

Strategies to prevent SARS-CoV-2 entry into the host cell aim to block the ACE2-RBD interaction. Although high-affinity monoclonal antibodies are leading the way as potential therapeutics $(20,23-30)$, they are expensive to produce by mammalian cell expression and need to be intravenously administered by healthcare professionals (31). Large doses are needed for prophylactic use, as only a small fraction of systemic antibodies cross the epithelial cell layers lining the airways (32). By contrast, nanobodies can be inexpensively produced in bacteria or yeast. The inherent stability of nanobodies enables aerosolized delivery directly to the nasal and lung epithelia (33). Indeed, aerosol delivery of a trimeric nanobody targeting respiratory syncytial virus (ALX-0171) was recently demonstrated to be effective in substantially decreasing measurable viral load in hospitalized infants (34). Finally, potential immunogenicity of camelid-derived nanobodies can be mitigated by established humanization strategies (35).

Nanobody multimerization has been shown to improve target affinity by avidity $(33,36)$. In the case of $\mathrm{Nb} 6$ and mNb6, structure-guided design of a multimeric construct that simultaneously engages all three RBDs yielded profound gains in potency. Furthermore, because RBDs must be in the up-state to engage with ACE2, conformational control of RBD accessibility serves as an added neutralization mechanism (30). Indeed, when mNb6-tri engages with Spike, it prevents ACE2 binding by both directly occluding the binding site and by locking the RBDs into an inactive conformation.

Our discovery of Class II neutralizing nanobodies demonstrates potentially novel mechanisms of disrupting Spike function. Pairing of Class I and Class II nanobodies in a prophylactic or therapeutic cocktail could provide both potent neutralization and prevention of escape variants (23). The combined stability, potency, and diverse epitope engagement of our anti-Spike nanobodies therefore provide a unique potential prophylactic and therapeutic strategy to limit the continued toll of the COVID-19 pandemic.

\section{REFERENCES AND NOTES}

1. T. G. Ksiazek, D. Erdman, C. S. Goldsmith, S. R. Zaki, T. Peret, S. Emery, S. Tong, C. Urbani, J. A. Comer, W. Lim, P. E. Rollin, S. F. Dowell, A.-E. Ling, C. D. Humphrey,
W.-J. Shieh, J. Guarner, C. D. Paddock, P. Rota, B. Fields, J. DeRisi, J.-Y. Yang, N. Cox, J. M. Hughes, J. W. LeDuc, W. J. Bellini, L. J. Anderson, SARS Working Group, A novel coronavirus associated with severe acute respiratory syndrome. N. Engl. J. Med. 348, 1953-1966 (2003). doi:10.1056/NEJMoa030781 Medline

2. A. M. Zaki, S. van Boheemen, T. M. Bestebroer, A. D. Osterhaus, R. A. Fouchier, Isolation of a novel coronavirus from a man with pneumonia in Saudi Arabia. N. Engl. J. Med. 367, 1814-1820 (2012). doi:10.1056/NEJMoa1211721 Medline

3. P. Zhou, X.-L. Yang, X.-G. Wang, B. Hu, L. Zhang, W. Zhang, H.-R. Si, Y. Zhu, B. Li, C.L. Huang, H.-D. Chen, J. Chen, Y. Luo, H. Guo, R.-D. Jiang, M.-Q. Liu, Y. Chen, X.-R. Shen, X. Wang, X.-S. Zheng, K. Zhao, Q.-J. Chen, F. Deng, L.-L. Liu, B. Yan, F.-X. Zhan, Y.-Y. Wang, G.-F. Xiao, Z.-L. Shi, A pneumonia outbreak associated with a new coronavirus of probable bat origin. Nature 579, 270-273 (2020). doi:10.1038/s41586-020-2012-7 Medline

4. J. F. Chan, S. Yuan, K.-H. Kok, K. K.-W. To, H. Chu, J. Yang, F. Xing, J. Liu, C. C.-Y. Yip, R. W.-S. Poon, H.-W. Tsoi, S. K.-F. Lo, K.-H. Chan, V. K.-M. Poon, W.-M. Chan, J. D. Ip, J.-P. Cai, V. C.-C. Cheng, H. Chen, C. K.-M. Hui, K.-Y. Yuen, A familial cluster of pneumonia associated with the 2019 novel coronavirus indicating person-toperson transmission: A study of a family cluster. Lancet 395, 514-523 (2020). doi:10.1016/S0140-6736(20)30154-9 Medline

5. C. Huang, Y. Wang, X. Li, L. Ren, J. Zhao, Y. Hu, L. Zhang, G. Fan, J. Xu, X. Gu, Z. Cheng, T. Yu, J. Xia, Y. Wei, W. Wu, X. Xie, W. Yin, H. Li, M. Liu, Y. Xiao, H. Gao, L. Guo, J. Xie, G. Wang, R. Jiang, Z. Gao, Q. Jin, J. Wang, B. Cao, Clinical features of patients infected with 2019 novel coronavirus in Wuhan, China. Lancet 395, 497506 (2020). doi:10.1016/S0140-6736(20)30183-5 Medline

6. F. Wu, S. Zhao, B. Yu, Y.-M. Chen, W. Wang, Z.-G. Song, Y. Hu, Z.-W. Tao, J.-H. Tian, Y.-Y. Pei, M.-L. Yuan, Y.-L. Zhang, F.-H. Dai, Y. Liu, Q.-M. Wang, J.-J. Zheng, L. Xu, E. C. Holmes, Y.-Z. Zhang, A new coronavirus associated with human respiratory disease in China. Nature 579, 265-269 (2020). doi:10.1038/s41586-020-2008-3 Medline

7. N. Zhu, D. Zhang, W. Wang, X. Li, B. Yang, J. Song, X. Zhao, B. Huang, W. Shi, R. Lu, P. Niu, F. Zhan, X. Ma, D. Wang, W. Xu, G. Wu, G. F. Gao, W. Tan, China Novel Coronavirus Investigating and Research Team, A novel coronavirus from patients with pneumonia in China, 2019. N. Engl. J. Med. 382, 727-733 (2020). doi:10.1056/NEJMoa2001017 Medline

8. Z. Ke, J. Oton, K. Qu, M. Cortese, V. Zila, L. McKeane, T. Nakane, J. Zivanov, C. J. Neufeldt, B. Cerikan, J. M. Lu, J. Peukes, X. Xiong, H.-G. Kräusslich, S. H. W. Scheres, R. Bartenschlager, J. A. G. Briggs, Structures and distributions of SARSCoV-2 spike proteins on intact virions. Nature (2020). doi:10.1038/s41586-0202665-2 Medline

9. B. Turoňová, M. Sikora, C. Schürmann, W. J. H. Hagen, S. Welsch, F. E. C. Blanc, S. von Bülow, M. Gecht, K. Bagola, C. Hörner, G. van Zandbergen, J. Landry, N. T. D. de Azevedo, S. Mosalaganti, A. Schwarz, R. Covino, M. D. Mühlebach, G. Hummer, J. Krijnse Locker, M. Beck, In situ structural analysis of SARS-CoV-2 spike reveals flexibility mediated by three hinges. Science 370, 203-208 (2020). doi:10.1126/science.abd5223 Medline

10. B. J. Bosch, R. van der Zee, C. A. de Haan, P. J. Rottier, The coronavirus spike protein is a class I virus fusion protein: Structural and functional characterization of the fusion core complex. J. Virol. 77, 8801-8811 (2003). doi:10.1128/JVI.77.16.8801-8811.2003 Medline

11. Y. Cai, J. Zhang, T. Xiao, H. Peng, S. M. Sterling, R. M. Walsh Jr., S. Rawson, S. RitsVolloch, B. Chen, Distinct conformational states of SARS-CoV-2 spike protein. Science 369, 1586-1592 (2020). doi:10.1126/science.abd4251 Medline

12. Q. Wang, Y. Zhang, L. Wu, S. Niu, C. Song, Z. Zhang, G. Lu, C. Qiao, Y. Hu, K.-Y. Yuen, Q. Wang, H. Zhou, J. Yan, J. Qi, Structural and functional basis of SARS-CoV2 entry by using human ACE2. Cell 181, 894-904.e9 (2020). doi:10.1016/i.cell.2020.03.045 Medline

13. R. Yan, Y. Zhang, Y. Li, L. Xia, Y. Guo, Q. Zhou, Structural basis for the recognition of SARS-CoV-2 by full-length human ACE2. Science 367, 1444-1448 (2020). doi:10.1126/science.abb2762 Medline

14. A. C. Walls, Y.-J. Park, M. A. Tortorici, A. Wall, A. T. McGuire, D. Veesler, Structure, function, and antigenicity of the SARS-CoV-2 spike glycoprotein. Cell 181, 281292.e6 (2020). doi:10.1016/j.cell.2020.02.058 Medline

15. D. Wrapp, N. Wang, K. S. Corbett, J. A. Goldsmith, C.-L. Hsieh, O. Abiona, B. S. Graham, J. S. McLellan, Cryo-EM structure of the 2019-nCoV spike in the prefusion conformation. Science 367, 1260-1263 (2020). 
doi:10.1126/science.abb2507 Medline

16. M. Hoffmann, H. Kleine-Weber, S. Schroeder, N. Krüger, T. Herrler, S. Erichsen, T. S. Schiergens, G. Herrler, N.-H. Wu, A. Nitsche, M. A. Müller, C. Drosten, S. Pöhlmann, SARS-CoV-2 cell entry depends on ACE2 and TMPRSS2 and is blocked by a clinically proven protease inhibitor. Cell 181, 271-280.e8 (2020). doi:10.1016/i.cell.2020.02.052 Medline

17. C. McMahon, A. S. Baier, R. Pascolutti, M. Wegrecki, S. Zheng, J. X. Ong, S. C. Erlandson, D. Hilger, S. G. F. Rasmussen, A. M. Ring, A. Manglik, A. C. Kruse, Yeast surface display platform for rapid discovery of conformationally selective nanobodies. Nat. Struct. Mol. Biol. 25, 289-296 (2018). doi:10.1038/s41594-0180028-6 Medline

18. S. Gupta, M. Sullivan, J. Toomey, J. Kiselar, M. R. Chance, The Beamline X28C of the Center for Synchrotron Biosciences: A national resource for biomolecular structure and dynamics experiments using synchrotron footprinting. J. Synchrotron Radiat. 14, 233-243 (2007). doi:10.1107/S0909049507013118 Medline

19. Y. Zhang, A. T. Wecksler, P. Molina, G. Deperalta, M. L. Gross, Mapping the binding interface of VEGF and a monoclonal antibody Fab-1 fragment with fast photochemical oxidation of proteins (FPOP) and mass spectrometry. J. Am. Soc. Mass Spectrom. 28, 850-858 (2017). doi:10.1007/s13361-017-1601-7 Medline

20. X. Chi, R. Yan, J. Zhang, G. Zhang, Y. Zhang, M. Hao, Z. Zhang, P. Fan, Y. Dong, Y. Yang, Z. Chen, Y. Guo, J. Zhang, Y. Li, X. Song, Y. Chen, L. Xia, L. Fu, L. Hou, J. Xu, C. Yu, J. Li, Q. Zhou, W. Chen, A neutralizing human antibody binds to the $\mathrm{N}$ terminal domain of the Spike protein of SARS-CoV-2. Science 369, 650-655 (2020). doi:10.1126/science.abc6952 Medline

21. H. Zhou, Y. Chen, S. Zhang, P. Niu, K. Qin, W. Jia, B. Huang, S. Zhang, J. Lan, L. Zhang, W. Tan, X. Wang, Structural definition of a neutralization epitope on the Nterminal domain of MERS-CoV spike glycoprotein. Nat. Commun. 10, 3068 (2019). doi:10.1038/s41467-019-10897-4 Medline

22. K. H. D. Crawford, R. Eguia, A. S. Dingens, A. N. Loes, K. D. Malone, C. R. Wolf, H. Y. Chu, M. A. Tortorici, D. Veesler, M. Murphy, D. Pettie, N. P. King, A. B. Balazs, J. D. Bloom, Protocol and reagents for pseudotyping lentiviral particles with SARSCoV-2 spike protein for neutralization assays. Viruses 12, 513 (2020). doi:10.3390/v12050513 Medline

23. A. Baum, B. O. Fulton, E. Wloga, R. Copin, K. E. Pascal, V. Russo, S. Giordano, K. Lanza, N. Negron, M. Ni, Y. Wei, G. S. Atwal, A. J. Murphy, N. Stahl, G. D. Yancopoulos, C. A. Kyratsous, Antibody cocktail to SARS-CoV-2 spike protein prevents rapid mutational escape seen with individual antibodies. Science $\mathbf{3 6 9}$, 1014-1018 (2020). Medline

24. Y. Cao, B. Su, X. Guo, W. Sun, Y. Deng, L. Bao, Q. Zhu, X. Zhang, Y. Zheng, C. Geng, X. Chai, R. He, X. Li, Q. Lv, H. Zhu, W. Deng, Y. Xu, Y. Wang, L. Qiao, Y. Tan, L. Song, G. Wang, X. Du, N. Gao, J. Liu, J. Xiao, X. D. Su, Z. Du, Y. Feng, C. Qin, C. Qin, R. Jin, X. S. Xie, Potent neutralizing antibodies against SARS-CoV-2 identified by highthroughput single-cell sequencing of convalescent patients' B cells. Cell 182, $73-$ 84.e16 (2020). doi:10.1016/i.cell.2020.05.025 Medline

25. B. Ju, Q. Zhang, J. Ge, R. Wang, J. Sun, X. Ge, J. Yu, S. Shan, B. Zhou, S. Song, X. Tang, J. Yu, J. Lan, J. Yuan, H. Wang, J. Zhao, S. Zhang, Y. Wang, X. Shi, L. Liu, J. Zhao, X. Wang, Z. Zhang, L. Zhang, Human neutralizing antibodies elicited by SARS-CoV-2 infection. Nature 584, 115-119 (2020). doi:10.1038/s41586-0202380-z Medline

26. L. Liu, P. Wang, M. S. Nair, J. Yu, M. Rapp, Q. Wang, Y. Luo, J. F.-W. Chan, V. Sahi, A. Figueroa, X. V. Guo, G. Cerutti, J. Bimela, J. Gorman, T. Zhou, Z. Chen, K.-Y. Yuen, P. D. Kwong, J. G. Sodroski, M. T. Yin, Z. Sheng, Y. Huang, L. Shapiro, D. D. Ho, Potent neutralizing antibodies against multiple epitopes on SARS-CoV-2 spike. Nature 584, 450-456 (2020). doi:10.1038/s41586-020-2571-7 Medline

27. D. Pinto, Y.-J. Park, M. Beltramello, A. C. Walls, M. A. Tortorici, S. Bianchi, S. Jaconi, K. Culap, F. Zatta, A. De Marco, A. Peter, B. Guarino, R. Spreafico, E. Cameroni, J. B. Case, R. E. Chen, C. Havenar-Daughton, G. Snell, A. Telenti, H. W. Virgin, A. Lanzavecchia, M. S. Diamond, K. Fink, D. Veesler, D. Corti, Cross-neutralization of SARS-CoV-2 by a human monoclonal SARS-CoV antibody. Nature 583, 290-295 (2020). doi:10.1038/s41586-020-2349-y Medline

28. T. F. Rogers, F. Zhao, D. Huang, N. Beutler, A. Burns, W. T. He, O. Limbo, C. Smith, G. Song, J. Woehl, L. Yang, R. K. Abbott, S. Callaghan, E. Garcia, J. Hurtado, M. Parren, L. Peng, S. Ramirez, J. Ricketts, M. J. Ricciardi, S. A. Rawlings, N. C. Wu, M. Yuan, D. M. Smith, D. Nemazee, J. R. Teijaro, J. E. Voss, I. A. Wilson, R. Andrabi,
B. Briney, E. Landais, D. Sok, J. G. Jardine, D. R. Burton, Isolation of potent SARSCoV-2 neutralizing antibodies and protection from disease in a small animal model. Science 369, 956-963 (2020). doi:10.1126/science. abc7520 Medline

29. S. J. Zost, P. Gilchuk, J. B. Case, E. Binshtein, R. E. Chen, J. P. Nkolola, A. Schäfer, J. X. Reidy, A. Trivette, R. S. Nargi, R. E. Sutton, N. Suryadevara, D. R. Martinez, L. E. Williamson, E. C. Chen, T. Jones, S. Day, L. Myers, A. O. Hassan, N. M. Kafai, E. S. Winkler, J. M. Fox, S. Shrihari, B. K. Mueller, J. Meiler, A. Chandrashekar, N. B. Mercado, J. J. Steinhardt, K. Ren, Y.-M. Loo, N. L. Kallewaard, B. T. McCune, S. P. Keeler, M. J. Holtzman, D. H. Barouch, L. E. Gralinski, R. S. Baric, L. B. Thackray, M. S. Diamond, R. H. Carnahan, J. E. Crowe Jr., Potently neutralizing and protective human antibodies against SARS-CoV-2. Nature 584, 443-449 (2020). doi:10.1038/s41586-020-2548-6 Medline

30. M. A. Tortorici, M. Beltramello, F. A. Lempp, D. Pinto, H. V. Dang, L. E. Rosen, M. McCallum, J. Bowen, A. Minola, S. Jaconi, F. Zatta, A. De Marco, B. Guarino, S. Bianchi, E. J. Lauron, H. Tucker, J. Zhou, A. Peter, C. Havenar-Daughton, J. A. Wojcechowskyj, J. B. Case, R. E. Chen, H. Kaiser, M. Montiel-Ruiz, M. Meury, N. Czudnochowski, R. Spreafico, J. Dillen, C. Ng, N. Sprugasci, K. Culap, F. Benigni, R. Abdelnabi, S. C. Foo, M. A. Schmid, E. Cameroni, A. Riva, A. Gabrieli, M. Galli, M. S. Pizzuto, J. Neyts, M. S. Diamond, H. W. Virgin, G. Snell, D. Corti, K. Fink, D. Veesler, Ultrapotent human antibodies protect against SARS-CoV-2 challenge via multiple mechanisms. Science eabe3354 (2020). doi:10.1126/science.abe3354 Medline

31. H. Ledford, Antibody therapies could be a bridge to a coronavirus vaccine - but will the world benefit? Nature 584, 333-334 (2020). doi:10.1038/d41586-02002360-y Medline

32. V. H. Leyva-Grado, G. S. Tan, P. E. Leon, M. Yondola, P. Palese, Direct administration in the respiratory tract improves efficacy of broadly neutralizing anti-influenza virus monoclonal antibodies. Antimicrob. Agents Chemother. 59, 4162-4172 (2015). doi:10.1128/AAC.00290-15 Medline

33. L. Detalle, T. Stohr, C. Palomo, P. A. Piedra, B. E. Gilbert, V. Mas, A. Millar, U. F. Power, C. Stortelers, K. Allosery, J. A. Melero, E. Depla, Generation and characterization of ALX-0171, a potent novel therapeutic nanobody for the treatment of respiratory syncytial virus infection. Antimicrob. Agents Chemother. 60, 6-13 (2015). doi:10.1128/AAC.01802-15 Medline

34. S. Cunningham, P. A. Piedra, F. Martinon-Torres, H. Szymanski, B. Brackeva, E. Dombrecht, L. Detalle, C. Fleurinck, RESPIRE study group, Nebulised ALX-0171 for respiratory syncytial virus lower respiratory tract infection in hospitalised children: A double-blind, randomised, placebo-controlled, phase $2 \mathrm{~b}$ trial. Lancet Respir. Med. S2213-2600(20)30320-9 (2020). doi:10.1016/S2213 2600(20)30320-9 Medline

35. C. Vincke, R. Loris, D. Saerens, S. Martinez-Rodriguez, S. Muyldermans, K. Conrath, General strategy to humanize a camelid single-domain antibody and identification of a universal humanized nanobody scaffold. J. Biol. Chem. 284, 3273-3284 (2009). doi:10.1074/jbc.M806889200 Medline

36. D. Wrapp, D. De Vlieger, K. S. Corbett, G. M. Torres, N. Wang, W. Van Breedam, K. Roose, L. van Schie, M. Hoffmann, S. Pöhlmann, B. S. Graham, N. Callewaert, B. Schepens, X. Saelens, J. S. McLellan, VIB-CMB COVID-19 Response Team, Structural basis for potent neutralization of betacoronaviruses by single-domain camelid antibodies. Cell 181, 1004-1015.e15 (2020). doi:10.1016/j.cell.2020.04.031 Medline

37. D. Stadlbauer, F. Amanat, V. Chromikova, K. Jiang, S. Strohmeier, G. A Arunkumar, J. Tan, D. Bhavsar, C. Capuano, E. Kirkpatrick, P. Meade, R. N. Brito, C. Teo, M. McMahon, V. Simon, F. Krammer, SARS-CoV-2 seroconversion in humans: A detailed protocol for a serological assay, antigen production, and test setup. Curr. Protoc. Microbiol. 57, e100 (2020). doi:10.1002/cpmc.100 Medline

38. I. Lui, X. X. Zhou, S. A. Lim, S. K. Elledge, P. Solomon, N. J. Rettko, B. S. Zha, L. L. Kirkemo, J. A. Gramespacher, J. Liu, F. Muecksch, J. C. C. Lorenzi, F. Schmidt, Y. Weisblum, D. F. Robbiani, M. C. Nussenzweig, T. Hatziioannou, P. D. Bieniasz, O. S. Rosenburg, K. K. Leung, J. A. Wells, Trimeric SARS-CoV-2 Spike interacts with dimeric ACE2 with limited intra-Spike avidity. bioRxiv 2020.2005.2021.109157 [Preprint]. 21 May 2020; https://doi.org/10.1101/2020.05.21.109157.

39. W. Kabsch, Automatic processing of rotation diffraction data from crystals of initially unknown symmetry and cell constants. J. Appl. Cryst. 26, 795-800 (1993). doi:10.1107/S0021889893005588

40. A. J. McCoy, R. W. Grosse-Kunstleve, P. D. Adams, M. D. Winn, L. C. Storoni, R. J. 
Read, Phaser crystallographic software. J. Appl. Crystallogr. 40, 658-674 (2007). doi:10.1107/S0021889807021206 Medline

41. P. D. Adams, P. V. Afonine, G. Bunkóczi, V. B. Chen, I. W. Davis, N. Echols, J. J. Headd, L.-W. Hung, G. J. Kapral, R. W. Grosse-Kunstleve, A. J. McCoy, N. W. Moriarty, R. Oeffner, R. J. Read, D. C. Richardson, J. S. Richardson, T. C. Terwilliger, P. H. Zwart, PHENIX: A comprehensive Python-based system for macromolecular structure solution. Acta Crystallogr. Sect. D Biol. Crystallogr. 66 , 213-221 (2010). doi:10.1107/S0907444909052925 Medline

42. G. Bricogne, E. Blanc, M. Brandl, C. Flensburg, P. Keller, W. Paciorek, P. Roversi, A. Sharff, O. S. Smart, C. Vonrhein, T. O. Womack, BUSTER version 1.10.0 (Global Phasing Ltd., Cambridge, UK, 2017).

43. P. Emsley, K. Cowtan, Coot: Model-building tools for molecular graphics. Acta Crystallogr. Sect. D Biol. Crystallogr. 60, 2126-2132 (2004). doi:10.1107/S0907444904019158 Medline

44. D. N. Mastronarde, Automated electron microscope tomography using robust prediction of specimen movements. J. Struct. Biol. 152, 36-51 (2005). doi:10.1016/i.jsb.2005.07.007 Medline

45. S. Q. Zheng, E. Palovcak, J.-P. Armache, K. A. Verba, Y. Cheng, D. A. Agard MotionCor2: Anisotropic correction of beam-induced motion for improved cryoelectron microscopy. Nat. Methods 14, 331-332 (2017). doi:10.1038/nmeth.4193 Medline

46. A. Punjani, J. L. Rubinstein, D. J. Fleet, M. A. Brubaker, cryoSPARC: Algorithms for rapid unsupervised cryo-EM structure determination. Nat. Methods 14, 290-296 (2017). doi:10.1038/nmeth.4169 Medline

47. J. Zivanov, T. Nakane, B. O. Forsberg, D. Kimanius, W. J. H. Hagen, E. Lindahl, S. H. W. Scheres, New tools for automated high-resolution cryo-EM structure determination in RELION-3. elife 7, e42166 (2018). doi:10.7554/eLife.42166 Medline

48. D. Asarnow, E. Palovcak, Y. Cheng, UCSF pyem v0.5 (Zenodo, 2019).

49. T. Grant, A. Rohou, N. Grigorieff, cisTEM, user-friendly software for single-particle image processing. elife 7, e35383 (2018). doi:10.7554/eLife.35383 Medline

50. T. D. Goddard, C. C. Huang, E. C. Meng, E. F. Pettersen, G. S. Couch, J. H. Morris, T. E. Ferrin, UCSF ChimeraX: Meeting modern challenges in visualization and analysis. Protein Sci. 27, 14-25 (2018). doi:10.1002/pro.3235 Medline

51. J. Lan, J. Ge, J. Yu, S. Shan, H. Zhou, S. Fan, Q. Zhang, X. Shi, Q. Wang, L. Zhang, X. Wang, Structure of the SARS-CoV-2 spike receptor-binding domain bound to the ACE2 receptor. Nature 581, 215-220 (2020). doi:10.1038/s41586-020-2180-5 Medline

52. S. G. Rasmussen, H.-J. Choi, J. J. Fung, E. Pardon, P. Casarosa, P. S. Chae, B. T. Devree, D. M. Rosenbaum, F. S. Thian, T. S. Kobilka, A. Schnapp, I. Konetzki, R. K. Sunahara, S. H. Gellman, A. Pautsch, J. Steyaert, W. I. Weis, B. K. Kobilka, Structure of a nanobody-stabilized active state of the $\beta_{2}$ adrenoceptor. Nature 469, 175-180 (2011). doi:10.1038/nature09648 Medline

53. B. Frenz, A. C. Walls, E. H. Egelman, D. Veesler, F. DiMaio, RosettaES: A sampling strategy enabling automated interpretation of difficult cryo-EM maps. Nat. Methods 14, 797-800 (2017). doi:10.1038/nmeth.4340 Medline

54. T. I. Croll, ISOLDE: A physically realistic environment for model building into lowresolution electron-density maps. Acta Crystallogr. D Struct. Biol. 74, 519-530 (2018). doi:10.1107/S2059798318002425 Medline

55. R. Y. Wang, Y. Song, B. A. Barad, Y. Cheng, J. S. Fraser, F. DiMaio, Automated structure refinement of macromolecular assemblies from cryo-EM maps using Rosetta. eLife 5, e17219 (2016). doi:10.7554/eLife.17219 Medline

56. B. Frenz, S. Rämisch, A. J. Borst, A. C. Walls, J. Adolf-Bryfogle, W. R. Schief, D. Veesler, F. DiMaio, Automatically fixing errors in glycoprotein structures with Rosetta. Structure 27, 134-139.e3 (2019). doi:10.1016/i.str.2018.09.006 Medline

57. J. Agirre, J. Iglesias-Fernández, C. Rovira, G. J. Davies, K. S. Wilson, K. D. Cowtan, Privateer: Software for the conformational validation of carbohydrate structures. Nat. Struct. Mol. Biol. 22, 833-834 (2015). doi:10.1038/nsmb.3115 Medline

58. M. D. Winn, C. C. Ballard, K. D. Cowtan, E. J. Dodson, P. Emsley, P. R. Evans, R. M. Keegan, E. B. Krissinel, A. G. W. Leslie, A. McCoy, S. J. McNicholas, G. N. Murshudov, N. S. Pannu, E. A. Potterton, H. R. Powell, R. J. Read, A. Vagin, K. S. Wilson, Overview of the CCP4 suite and current developments. Acta Crystallogr. Sect. D Biol. Crystallogr. 67, 235-242 (2011). doi:10.1107/S0907444910045749 Medline

59. V. B. Chen, W. B. Arendall III, J. J. Headd, D. A. Keedy, R. M. Immormino, G. J.
Kapral, L. W. Murray, J. S. Richardson, D. C. Richardson, MolProbity: All-atom structure validation for macromolecular crystallography. Acta Crystallogr. Sect. D Biol. Crystallogr. 66. 12-21 (2010). doi:10.1107/S0907444909042073 Medline

60. B. A. Barad, N. Echols, R. Y.-R. Wang, Y. Cheng, F. DiMaio, P. D. Adams, J. S. Fraser, EMRinger: Side chain-directed model and map validation for 3D cryo-electron microscopy. Nat. Methods 12, 943-946 (2015). doi:10.1038/nmeth.3541 Medline

61. D. P. Staus, R. T. Strachan, A. Manglik, B. Pani, A. W. Kahsai, T. H. Kim, L. M. Wingler, S. Ahn, A. Chatterjee, A. Masoudi, A. C. Kruse, E. Pardon, J. Steyaert, W. I. Weis, R. S. Prosser, B. K. Kobilka, T. Costa, R. J. Lefkowitz, Allosteric nanobodies reveal the dynamic range and diverse mechanisms of G-protein-coupled receptor activation. Nature 535, 448-452 (2016). doi:10.1038/nature18636 Medline

62. F. Yu, S. E. Haynes, G. C. Teo, D. M. Avtonomov, D. A. Polasky, A. I. Nesvizhskii, Fast quantitative analysis of timsTOF PASEF data with MSFragger and lonQuant. Mol. Cell. Proteomics 19, 1575-1585 (2020). doi:10.1074/mcp.TIR120.002048 Medline

63. M. Choi, C.-Y. Chang, T. Clough, D. Broudy, T. Killeen, B. MacLean, O. Vitek, MSstats: An R package for statistical analysis of quantitative mass spectrometrybased proteomic experiments. Bioinformatics 30, 2524-2526 (2014). doi:10.1093/bioinformatics/btu305 Medline

\section{ACKNOWLEDGMENTS}

We thank the entire Walter and Manglik labs for facilitating the development and rapid execution of this large-scale collaborative effort. We thank Sebastian Bernales and Tony De Fougerolles for advice and helpful discussion, and Jonathan Weissman for input into the project and reagent and machine use. We thank Jim Wells for providing the ACE2 ECD-Fc construct, Jason McLellan for providing Spike, RBD, and ACE2 constructs, and Florian Krammer for providing an RBD construct. We thank Jesse Bloom for providing the ACE2 expressing HEK293T cells as well as the plasmids for pseudovirus work. We thank George Meigs and other Beamline staff at ALS, 8.3.1 for their help in data collection. We thank Randy A. Albrecht for oversight of the conventional BSL3 biocontainment facility at the Icahn School of Medicine at Mount Sinai. Funding: This work was supported by the UCSF COVID-19 Response Fund, a grant from Allen \& Company, and supporters of the UCSF Program for Breakthrough Biomedical Research (PBBR), which was established with support from the Sandler Foundation. Further support was provided by the National Institutes of Health (NIH) grant DP50D023048 (A.Manglik). Cryo-EM equipment at UCSF is partially supported by NIH grants S100D020054 and S100D021741. Work by M.Vignuzzi was funded by the Laboratoire d'Excellence grant ANR-10-LABX-62-IBEID and the URGENCE COVID-19 Institut Pasteur fundraising campaign. The radiolytic hydroxyl radical footprinting is supported by NIH 1R01GM126218. The Advanced Light Source is supported by the Office of Science, Office of Biological and Environmental Research, of the U.S. DOE under contract DE-AC02-05CH11231. S.Sangwan was supported by a Helen Hay Whitney postdoctoral fellowship. C.B.Billesbølle acknowledges support from the Alfred Benzon Foundation. K.Leon was funded by NIH/NINDS award F31NS113432 and a UCSF Discovery Fellowship from the Otellini Family. C.Puchades and V.Belyy are Fellows of the Damon Runyon Cancer Research Foundation. H.Kratochvil and U.S.Chio were supported by Ruth L. Kirschstein NRSA Postdoctoral Fellowships (F32GM125217 and F32GM137463). This research was also partly funded by CRIP (Center for Research for Influenza Pathogenesis), a NIAID supported Center of Excellence for Influenza Research and Surveillance (CEIRS, contract \# HHSN272201400008C), by DARPA grant HR0011-19-2-0020, by an administrative supplement to NIAID grant U19AI142733, and by the generous support of the JPB Foundation and the Open Philanthropy to A.Garcia-Sastre. M.Ott acknowledges support through a gift from the Roddenberry Foundation. P.Walter is an Investigator of the Howard Hughes Medical Institute. A.Manglik acknowledges support from the Pew Charitable Trusts, the Esther and A. \& Joseph Klingenstein Fund and the Searle Scholars Program. Author contributions: M.Schoof purified Spike ${ }^{\text {S2P }}$, RBD, and ACE2 proteins, performed yeast display selections to identify and affinity mature nanobodies, expressed and purified nanobodies, tested activity in cell-based assays, cloned, expressed, and purified multivalent nanobody constructs, and coordinated live virus experiments. B.Faust purified and characterized Spike ${ }^{\mathrm{S} 2 \mathrm{P}}$ protein and candidate nanobodies, developed, performed and analyzed SPR experiments for Spike $e^{\text {S2P }}$ 
and RBD-nanobody affinity determination, developed, performed and analyzed SPR binning, experiments, determined optimal freezing conditions for cryo-EM experiments, processed, refined and generated figures for $\mathrm{Nb6}, \mathrm{Nb} 11$, and $\mathrm{mNb} 6$ EM datasets. R.A. Saunders expressed and purified ACE2 and nanobodies, developed and performed cell-based assays for inhibition of Spike ${ }^{\mathrm{S} 2 \mathrm{P}}$ binding and pseudovirus assays for determining nanobody efficacy. S.Sangwan expressed and purified Spike ${ }^{\mathrm{S} 2 \mathrm{P}}$, RBD, ACE2-Fc, and nanobodies, processed cryo-EM data, optimized RBD-nanobody complexes for crystallography, grew crystals of mNb6, collected diffraction data, and refined the X-ray crystal structure of mNb6. V.Rezelj tested efficacy of nanobody constructs in live SARS-CoV-2 infection assays under the guidance of M.Vignuzzi. N.Hoppe purified nanobodies, developed, performed and analyzed SPR binning experiments, developed performed and analyzed variable Nb6-bi and Nb6-tri association experiments, and performed thermal melting stability assays for nanobody constructs. M. Boone developed approaches to express and purify nanobodies from Pichia pastoris and developed, performed, and analyzed approaches to quantify nanobody efficacy in live virus assays. C.B.Billesbølle expressed and purified Spike ${ }^{\text {S2P }}$, generated affinity maturation library for Nb6, performed yeast display selections to identify mNb6, and built the synthetic yeast nanobody library with J.Liang. I.Deshpande expressed and purified nanobody constructs. B.S.Zha performed live SARS-CoV-2 virus assays to test nanobody efficacy with guidance from 0.Rosenberg. C.R.Simoneau and K.Leon performed live SARS-CoV-2 virus assays to test nanobody efficacy with guidance from M.Ott. K.M.White performed live SARS-CoV-2 virus assays to test nanobody efficacy with guidance from A.Garcia-Sastre. A.W.Barile-Hill performed SPR experiments. A.A.Anand, N.Dobzinski, B.Barsi-Rhyne, and Y.Liu. assisted in cloning, expression, and purification of nanobody and pseudovirus constructs. V.Belyy performed singlemolecule nanobody-Spike ${ }^{22 P}$ interaction studies. S.Nock prepared media and coordinated lab usage during UCSF's partial shutdown. M.Zimanyi and S.Gupta performed radiolytic footprinting experiments with guidance from C.Y.Ralston and analyzed mass spectrometry data generated by D.L.Swaney. Several members of the QCRG Structural Biology Consortium played an exceptionally important role for this project. C.Azumaya and C.Puchades determined optimal freezing conditions for cryo-EM experiments, optimized data collection approaches, and collected cryo-EM datasets. A.F.Brilot, A.Rizo, A.M.Smith, F.Moss, D.Bulkley, T.Popsiech collected cryo-EM data on Spike ${ }^{\text {S2P-nanobody }}$ complexes. S.Dickinson, H.C.Nguyen, C.M.Chio, U.S.Chio, M.Gupta, M.Jin, F.Li, Y.Liu, G.E.Merz, K.Zhang, M.Sun analyzed cryo-EM data from 15 Spike ${ }^{\text {S2P. }}$ nanobody complex datasets. H.T.Kratochvil set up crystallization trials of various RBD-nanobody complexes, and crystallized, collected diffraction data for, and refined the $\mathrm{mNb6}$ structure. M.C.Thompson collected, processed, and refined the mNb6 structure. R.Trenker, D.Diwanji, K.Schaefer expressed and purified Spike ${ }^{\text {S2P }}$, and S.Pourmal purified RBD. A.Manglik expressed and purified Spike ${ }^{\text {S2P, }}$ labeled Spike ${ }^{\text {S2P }}$ for biochemical studies, designed selection strategies for nanobody discovery, cloned nanobodies for expression, designed affinity maturation libraries and performed selections, analyzed SPR data, and performed nanobody stability studies. The overall project was supervised by P.Walter and A.Manglik. Competing interests: M.Schoof, B.Faust, R.A.Saunders, N.Hoppe, P.Walter, and A.Manglik are inventors on a provisional patent describing anti-Spike nanobodies described in this manuscript. P. Walter is a cofounder and consultant to Praxis Biotech LLC, with an equity interest in the company. The García-Sastre Laboratory has received research support from Pfizer, Senhwa Biosciences, Kenall Manufacturing, Light Sources and 7Hills Pharma. A.García-Sastre has consulting agreements for the following companies involving cash and/or stock: Vivaldi Biosciences, Contrafect, 7Hills Pharma, Avimex, Valneva, Accurius and Esperovax. Data and materials availability: All data generated or analyzed during this study are included in this published article and its Supplementary Materials. Crystallographic coordinates and structure factors for mNb6 have been deposited in the Protein Data Bank under accession code 7KKJ. Coordinates for Spike ${ }^{\text {S2P. }}$ Nb6 and Spike ${ }^{\text {S2P: }}$ :mNb6 complexes have been deposited in the Protein Data Bank under accession codes 7KKK and 7KKL, respectively. Maps for Spike ${ }^{\text {S2P: }}$ Nb6, Spike ${ }^{\text {S2P:Nb11, and }}$ Spike ${ }^{\text {S2P. }} \mathrm{mN} 6$ have been deposited in the Electron Microscopy Data Bank under

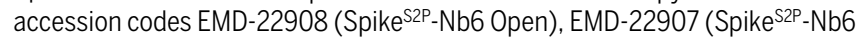

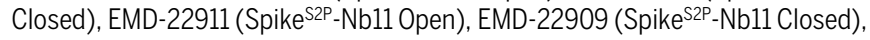

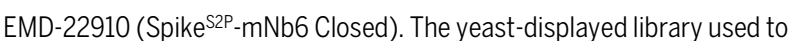
generate nanobodies in this study and the plasmids for nanobody constructs used in this study are available under a Material Transfer Agreement with the University of California, San Francisco. This work is licensed under a Creative Commons Attribution 4.0 International (CC BY 4.0) license, which permits unrestricted use, distribution, and reproduction in any medium, provided the original work is properly cited. To view a copy of this license, visit

https://creativecommons.org/licenses/by/4.0/. This license does not apply to figures/photos/artwork or other content included in the article that is credited to a third party; obtain authorization from the rights holder before using such material.

\section{SUPPLEMENTARY MATERIALS}

science.sciencemag.org/cgi/content/full/science.abe3255/DC1

Materials and Methods

Figs. S1 to $S 9$

Tables S1 to S4

QCRG Structural Biology Consortium Author List

References (37-63)

MDAR Reproducibility Checklist

15 August 2020; accepted 30 October 2020

Published online 5 November 2020

10.1126/science.abe3255 
A

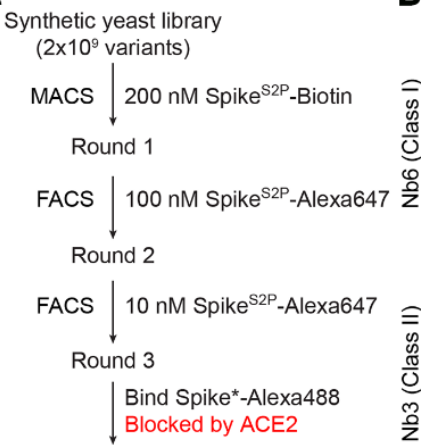

| Bind Spike*-Alexa488 Blocked by ACE2

21 unique clones

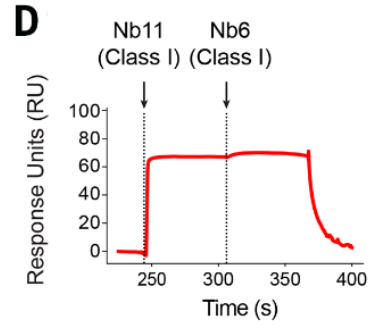

B
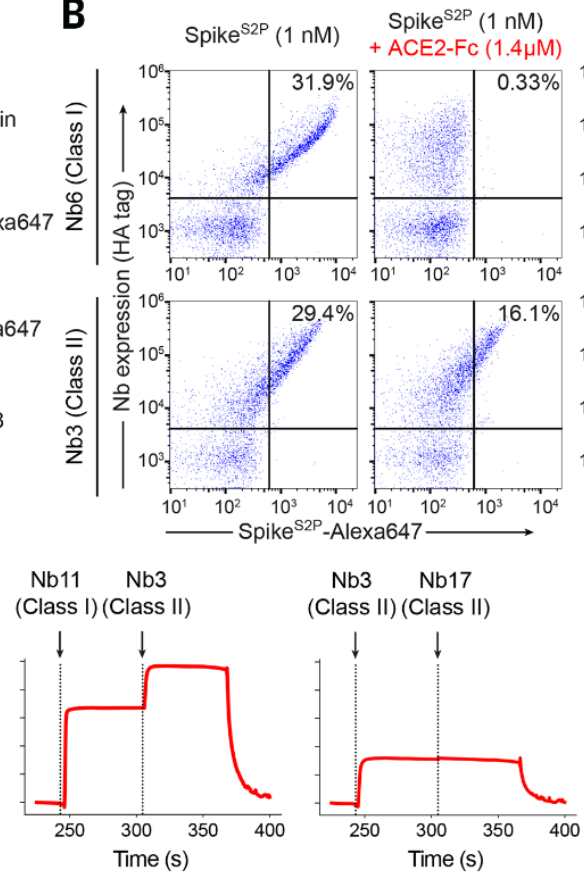
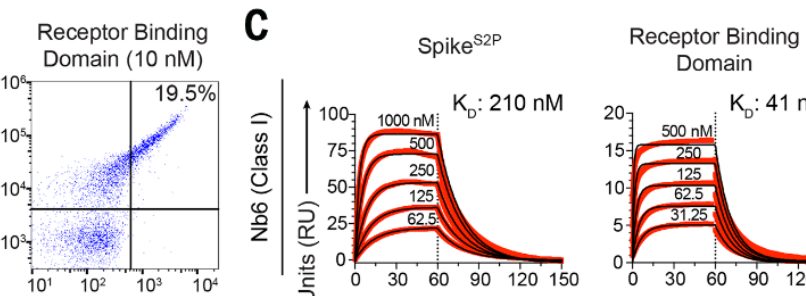
Domain
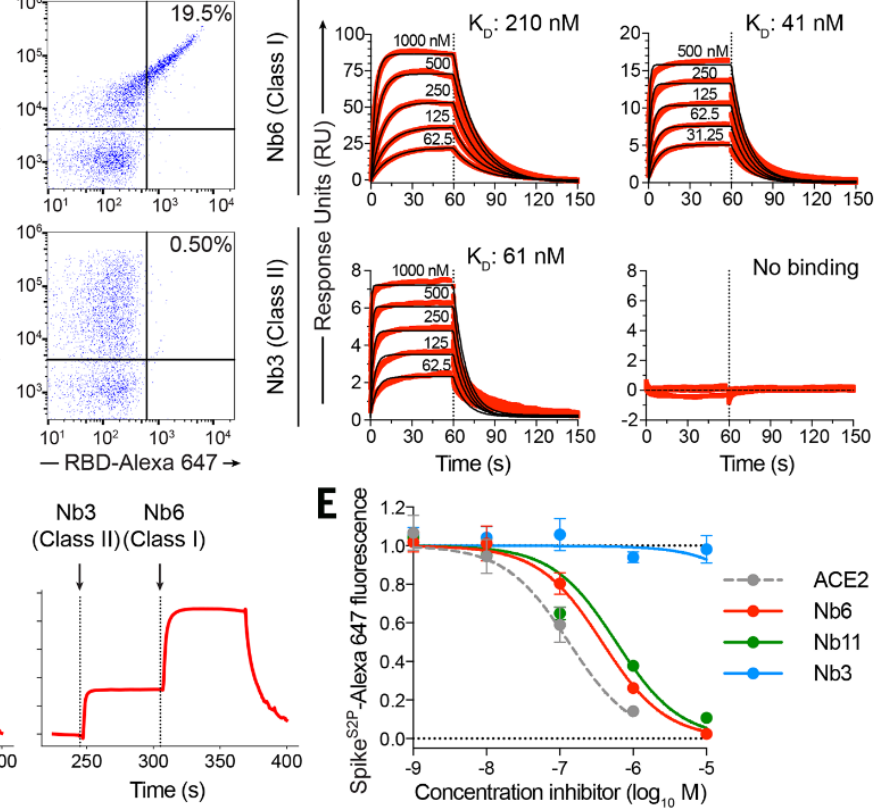

Fig. 1. Discovery of two distinct classes of anti-Spike nanobodies. (A) Selection strategy for identification of anti-Spike nanobodies that disrupt Spike-ACE2 interactions using magnetic bead selections (MACS) or fluorescence activated cell sorting (FACS). (B) Flow cytometry of yeast displaying Nb6 (a Class I nanobody) or Nb3 (a Class II nanobody). Nb6 binds Spike ${ }^{\mathrm{S2P}}$-Alexa 647 and receptor binding domain (RBD-Alexa 647). Nb6 binding to Spike ${ }^{\mathrm{S2P}}$ is completely disrupted by an excess $(1.4 \mu \mathrm{M})$ of ACE2-Fc. Nb3 binds Spike ${ }^{\mathrm{S} 2 \mathrm{P}}$, but not the RBD. Nb3 binding to Spike ${ }^{\mathrm{S} 2 \mathrm{P}}$ is partially decreased by ACE2-Fc. (C) SPR of Nb6 and Nb3 binding to either Spike ${ }^{\mathrm{S} 2 \mathrm{P}}$ or RBD. Red traces are raw data and global kinetic fits are shown in black. Nb3 shows no binding to RBD. (D) SPR experiments with immobilized Spike ${ }^{\mathrm{S} 2 \mathrm{P}}$ show that Class I and Class II nanobodies can bind Spike $\mathrm{S}^{\mathrm{SP}}$ simultaneously. By contrast, two Class I nanobodies or Class II nanobodies do not bind simultaneously. (E) Nanobody inhibition of $1 \mathrm{nM}$ Spike ${ }^{\mathrm{S} 2 \mathrm{P}}$-Alexa 647 binding to ACE2 expressing HEK293T cells. $n=3$ (ACE2, Nb3) or 5 (Nb6, Nb11) biological replicates. All error bars represent s.e.m. 
A

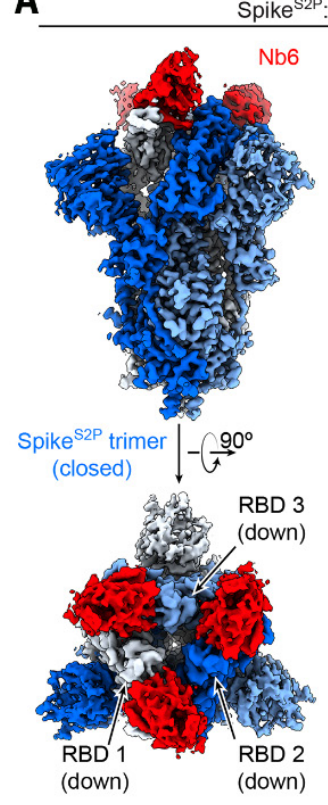

C

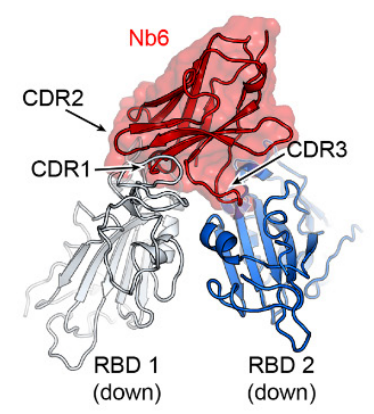

B
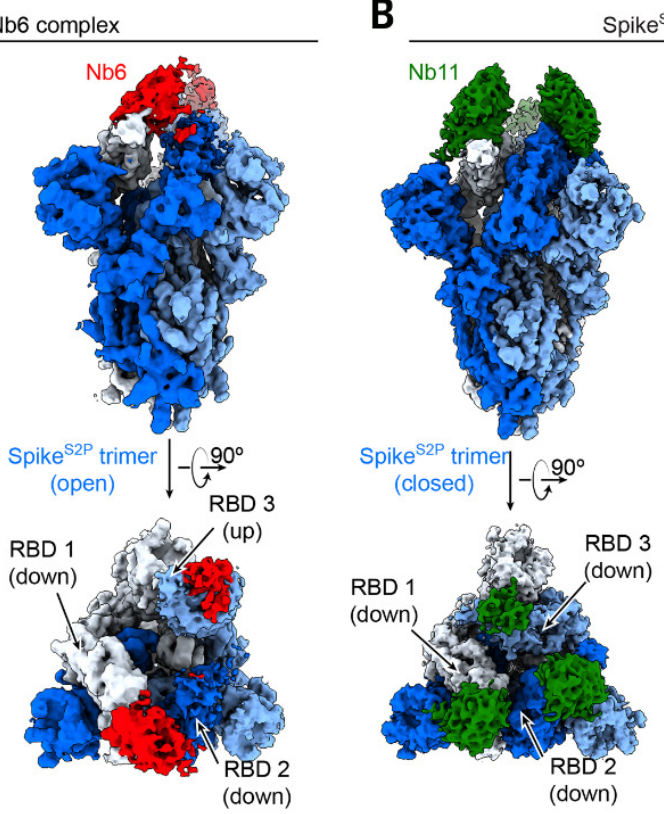

Spike ${ }^{\mathrm{S} 2 \mathrm{P}}:$ Nb11 complex
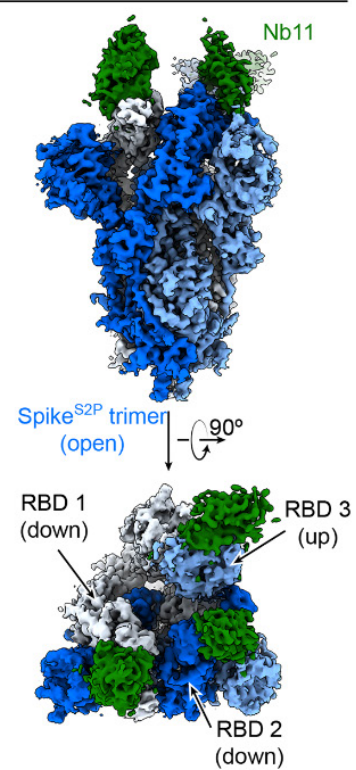

D

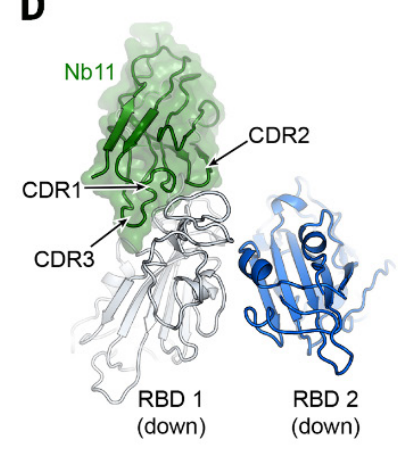

E

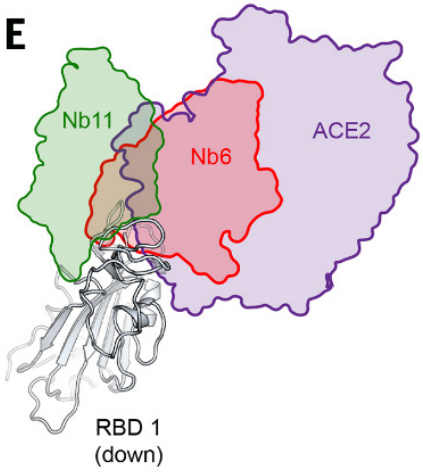

Fig. 2. Cryo-EM structures of $\mathrm{Nb} 6$ and $\mathrm{Nb11}$ bound to Spike. (A) Cryo-EM maps of Spike ${ }^{\mathrm{S} 2 \mathrm{P}-\mathrm{Nb} 6}$ complex in either closed (left) or open (right) Spike ${ }^{\mathrm{S} 2 \mathrm{P}}$ conformation. (B) Cryo-EM maps of Spike ${ }^{\mathrm{S} 2 \mathrm{P}}$ $\mathrm{Nb} 11$ complex in either closed (left) or open (right) Spike ${ }^{\mathrm{S2P}}$ conformation. The top views show receptor binding domain (RBD) up- or down-states. (C) Nb6 straddles the interface of two downstate RBDs, with CDR3 reaching over to an adjacent RBD. (D) Nb11 binds a single RBD in the downstate (displayed) or similarly in the up-state. No cross-RBD contacts are made by Nb11 in either RBD up- or down-state. (E) Comparison of RBD epitopes engaged by ACE2 (purple), Nb6 (red), or Nb11 (green). Both Nb11 and Nb6 directly compete with ACE2 binding. 


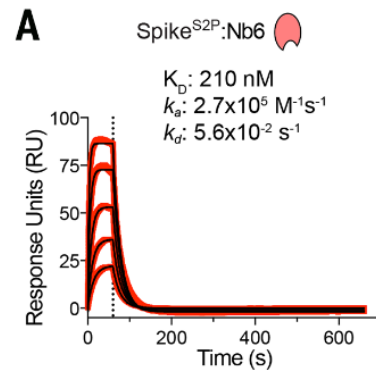

C

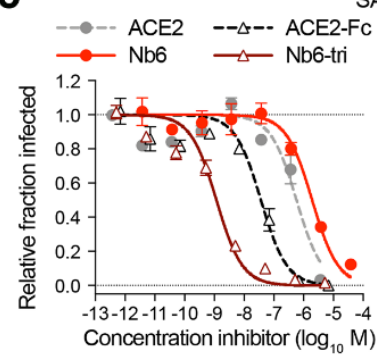

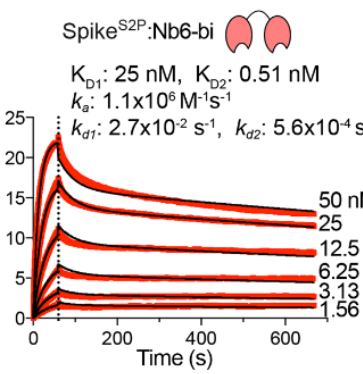

SARS-CoV-2 Spike Pseudotyped Lentivirus

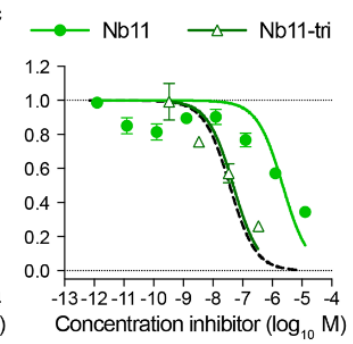

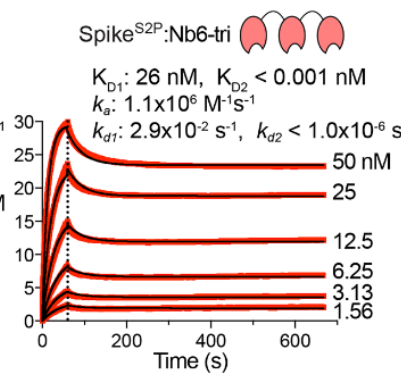

D

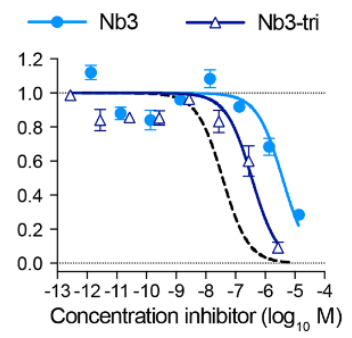

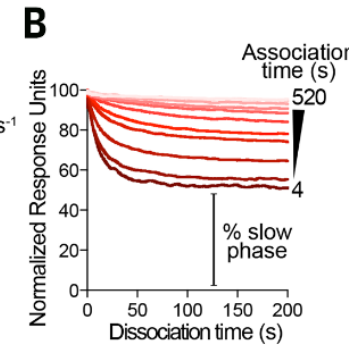

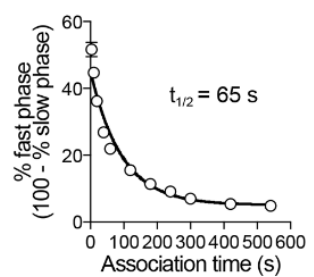

Live SARS-CoV-2 (France/IDF0372/2020)
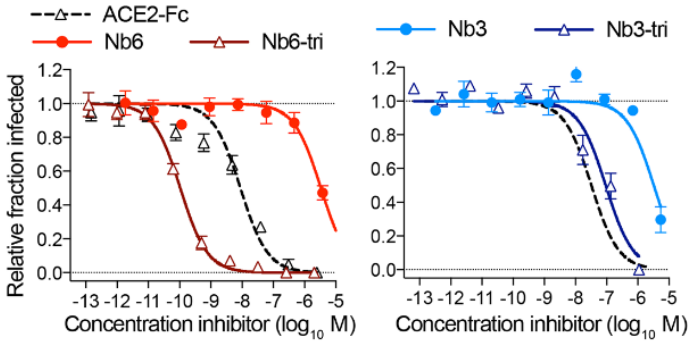

Fig. 3. Multivalency improves nanobody affinity and inhibitory efficacy. (A) SPR of Nb6 and multivalent variants. Red traces show raw data and black lines show global kinetic fit for Nb6 and independent fits for association and dissociation phases for Nb6-bi and Nb6-tri. (B) Dissociation phase SPR traces for Nb6-tri after variable association time ranging from 4 to $520 \mathrm{~s}$. Curves were normalized to maximal signal at the beginning of the dissociation phase. Percent fast phase is plotted as a function of association time (right) with a single exponential fit. $\mathrm{n}=3$ independent biological replicates. (C) Inhibition of pseudotyped lentivirus infection of ACE2 expressing HEK293T cells. $n=3$ biological replicates for all but Nb11-tri $(n=2)$. (D) Inhibition of live SARS-CoV-2 virus. Representative biological replicate with $n=3$ (right panel) or 4 (left panel) technical replicates per concentration. $\mathrm{n}=3$ biological replicates for all but Nb3 and Nb3-tri $(n=2)$. All error bars represent s.e.m. 
A
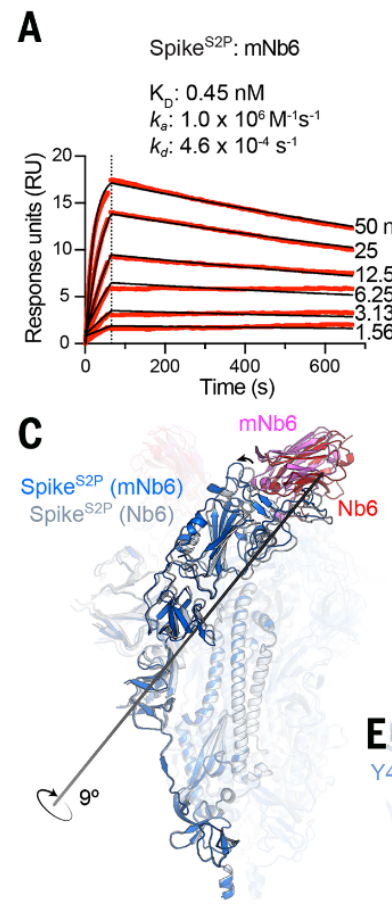

Spike ${ }^{\mathrm{S} 2 \mathrm{P}}: \mathrm{mNb6}$-tri

$\mathrm{K}_{\mathrm{p}}<0.001 \mathrm{nM}$

$k_{a}: 1.4 \times 10^{6} \mathrm{M}^{-1} \mathrm{~S}^{-1}$

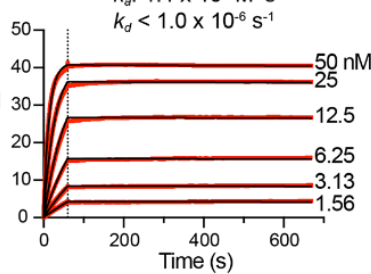

D

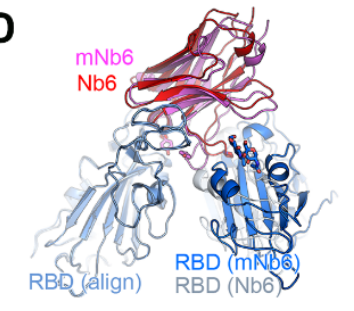

B

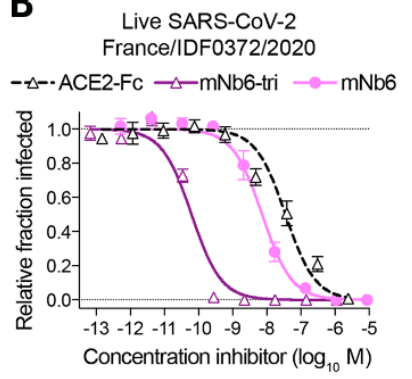

G
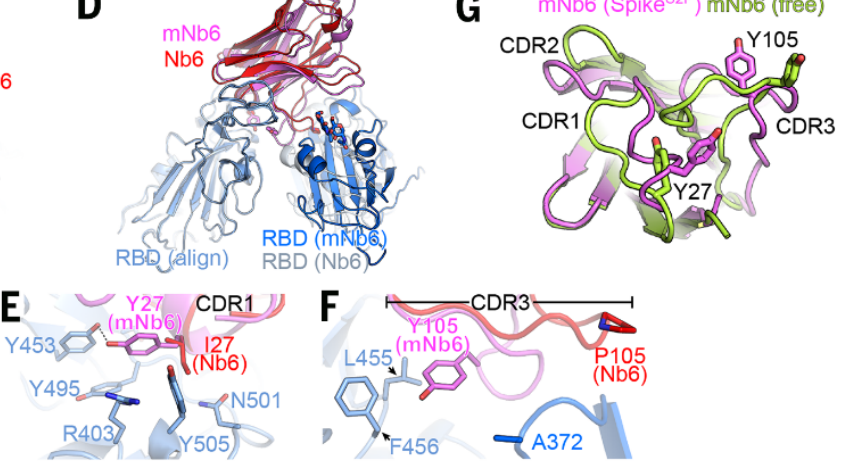

Fig. 4. Affinity maturation of Nb6 yields a picomolar SARS-CoV-2 neutralizing molecule. (A) SPR of $\mathrm{mNb} 6$ and $\mathrm{mNb} 6$-tri binding to immobilized Spike ${ }^{\mathrm{S} 2 \mathrm{P}}$. Red traces show raw data and black lines show global kinetic fit. No dissociation was observed for mNb6-tri over 10 min. (B) mNb6 and mNb6tri inhibit SARS-CoV-2 infection of VeroE6 cells in a plaque assay. Representative biological replicate with $n=4$ technical replicates per concentration. $n=3$ biological replicates for all samples. All error bars represent s.e.m. (C) Comparison of closed Spike ${ }^{\mathrm{S} 2 \mathrm{P}}$ bound to $\mathrm{mNb6}$ and Nb6. Rotational axis for RBD movement is highlighted. (D) Comparison of receptor binding domain (RBD) engagement by $\mathrm{Nb6}$ and $\mathrm{mNb6}$. One RBD was used to align both structures (RBD align), demonstrating changes in $\mathrm{Nb} 6$ and $\mathrm{mNb} 6$ position and the adjacent RBD. (E) CDR1 of Nb6 and $\mathrm{mNb} 6$ binding to the RBD. As compared to 127 in Nb6, Y27 of mNb6 hydrogen bonds to Y453 and optimizes pi-pi and pi-cation interactions with the RBD. (F) CDR3 of Nb6 and mNb6 binding to the RBD demonstrating a large conformational rearrangement of the entire loop in $\mathrm{mNb6}$. (G) Comparison of $\mathrm{mNb} 6$ complementarity determining regions in either the cryo-EM structure of the Spike ${ }^{\mathrm{S} 2 \mathrm{P}}-\mathrm{mNb} 6$ complex or an X-ray crystal structure of mNb6 alone. 
A
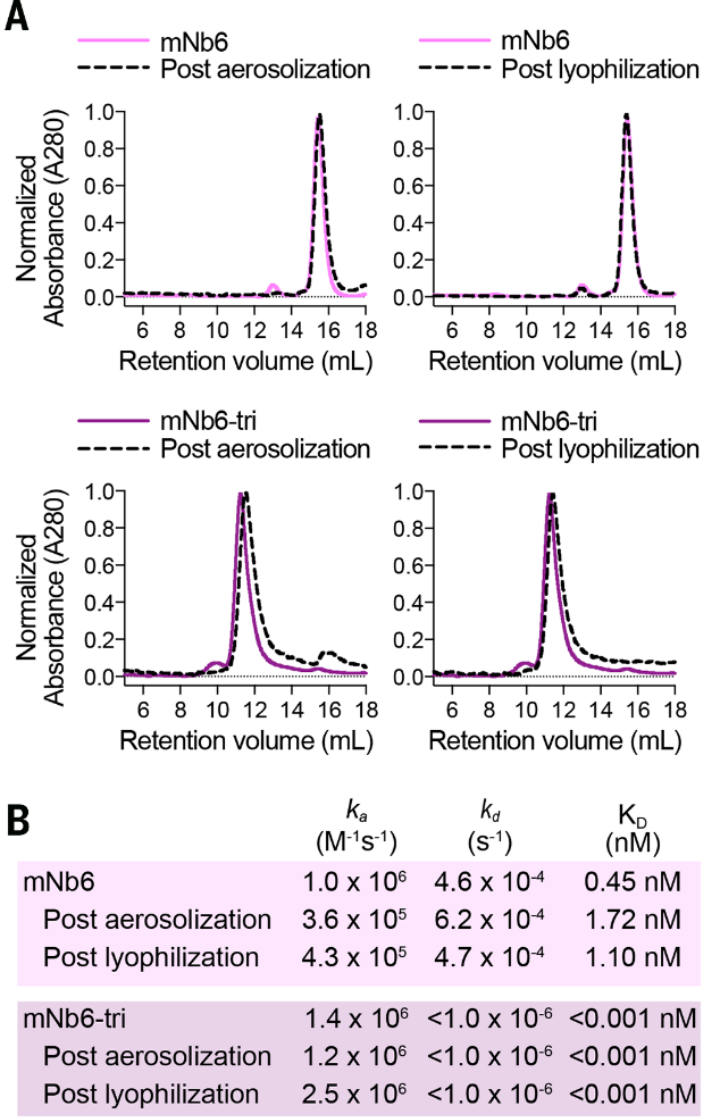

C Live SARS-CoV-2

France/IDF0372/2020
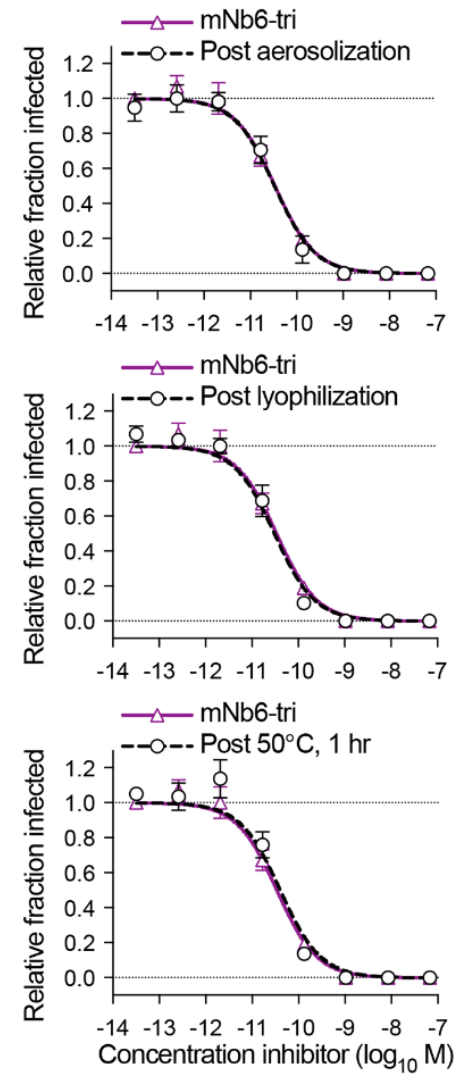

Fig. 5. mNb6 and mNb6-tri retain activity after aerosolization, lyophilization, and heat treatment. (A) Size exclusion chromatography of nanobodies after lyophilization or aerosolization. (B) Summary table of SPR kinetics data and affinities for aerosolized or lyophilized mNb6 and mNb6tri. (C) Inhibition of SARS-CoV-2 infection of VeroE6 cells by mNb6-tri after aerosolization, lyophilization, or heat treatment at $50^{\circ} \mathrm{C}$ for 1 hour. Representative biological replicate with $n=2$. Technical replicates $n=3$ per concentration. 